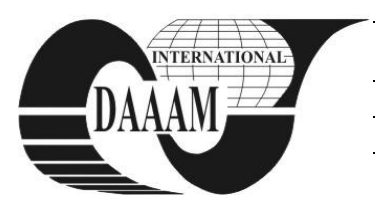

Annals of DAAAM for 2012 \& Proceedings of the 23rd International DAAAM Symposium, Volume 23, No.1, ISSN 2304-1382 ISBN 978-3-901509-91-9, CDROM version, Ed. B. Katalinic, Published by DAAAM International, Vienna, Austria, EU, 2012 Make Harmony between Technology and Nature, and Your Mind will Fly Free as a Bird

\title{
STUDIES AND RESEARCHES ABOUT FORMATION OF NONLINEAR VISCOELASTIC NON-NEWTONIAN MIXTURES
}

\author{
JUDELE, A[drian] \& SAVIN, C[armen]
}

\begin{abstract}
The paper analyzed the apparent structural viscosity variations of nonlinear viscoelastic non-Newtonian mixtures in function of the revolution of the mixing device and phase's temperature. For the proposed study there were analyzed binary non-Newtonian mixtures by type $L-S$ and $S-L$ with different concentrations obtained in laboratory. The apparent structural viscosity determination was carried out analytically correlating the deformation state of mixing device's shaft whit the torsion moment value.

Keywords: apparent structural viscosity, torsion moment, nonNewtonian mixtures by type $L-S$ and $S-L$, viscoelastic product, elastoplastic product, viscoplastic product
\end{abstract}

\section{INTRODUCTION}

The food products are corps with a very complex structure, in particular solid liquid mixtures, which have properties varying in time. From this point of view we are talking about viscoelastic, elastoplastic and viscoplastic products $[1,2,3,4,6]$.

Bread dough's are part of viscoelastic products. In dough formation, rheological properties exprime the deformation in time of the dough under the action of external forces, which exercise on it $[1,5,6,7]$.

Wheat flour dough is a linear viscoelastic corp. It has properties that are characteristic for solids and liquids and, therefore, has an intermediate behavior between solid corps and ideal fluids. When dough is subject to solicitations, some energy is dissipated and the rest of it is stored elsewhere. After unloading, the deformation is partly recovered $[1,2,3,4]$.

Rheological properties of dough are: elasticity, viscosity, relaxation, creep [1, 2, 3, 4].

\section{THE ANALYTICAL DETERMINATION OF STRUCTURAL APPARENT VISCOSITY}

The viscoelastic mixture shows the viscous liquid phases and elastic solid phases also. They are characterized by the fact that under the action of the solicitations, are deform continuous in time, flow without reaching a steady state of deformation and apparent structural viscosity is a measure of the resistance forces. After removing the application, because of elastic component, a part of strain is recovered [2, 3, 5, 6, 7]. In the literature, the analytic determination of viscosity is performed by evaluation of viscosity force opposed to a rotational corps, starting to the fundamental assumption of Newton, and sizes of the rotational corp. But, the nonNewtonian mixtures present deviations to the Newtonian behavior $[3,4,5,6,7]$.

In food industry, the non-Newtonian mixtures are characterized by their resistance to flow. This is change with the change rate of applied shear force, so their flow is uneven. The non-Newtonian mixtures are called abnormal viscous mixtures when can't be characterized by a constant value of viscosity for a specified temperature $[3,5,6]$.

In this case, the analytic determination of apparent structural viscosity was realized taking in consideration the action and distribution of shearing strains inside of mixture, to the mixing device. After the action of shearing strains created in mixture mass, to mixing device, in mixing device shaft appear deformations (according to action/reaction principle). The values of deformations are transformed, helped by a soft, in values of the torsion moment [5].

Taking in consideration the information's above, in laboratory, it was tried the determination of apparent structural viscosity based on measure of resistance opposed by a non-Newtonian mixture to a mixing device in rotation movement. It was started from the idea that this resistance opposed by non-Newtonian mixture generates in mixing device shaft a deformation state which can be correlated with torsion moment value [5]. Based on these considerations, the apparent structural viscosity relationship for calculating the structural form is given use 1 [5]:

$$
\eta_{a}=\frac{c \cdot M_{t}}{\pi \cdot \omega \cdot R^{3}}(\mathrm{~Pa} \cdot \mathrm{s})
$$

where: $c$ material rheological constant; $c=1.5$ for mixing device with 2 arms and

$\mathrm{c}=3$ for mixing device with 4 arms;

$\omega-$ the angular velocity of the mixing device, $\mathrm{s}^{-1}$;

$M_{t}$ - the torsion moment from mixing devices shaft, $\mathrm{N} \cdot \mathrm{m}$;

$R$ - the circle radius described by mixing devices arm, $\mathrm{m}$

\section{THE MATERIAL AND RESEARCH METHODOLOGY}

To realize the experiences, it was analyzed binary non-Newtonian mixtures by type $\mathrm{L}-\mathrm{S}$ and $\mathrm{S}-\mathrm{L}$, 
characterized by variable viscosity with different concentrations (table 1, 2 and 3) to represent a wide range of dough's with variable viscosity. Depending on the phase's participation, it was realized following types of non-Newtonian mixtures:

- Non-Newtonian mixture by soft consistency, characterized by solid phase participation in rate of $25 \%$;

- Non-Newtonian mixture by medium consistency, characterized by solid phase participation in rate of $50 \%$;

- Non-Newtonian mixture by strong consistency, solid phase characterized by participation in rate of $75 \%$.

The study of the mixing process for achieving the three types of non-Newtonian mixtures with variable viscosity was realized by mixing phases depending on the density of the two phases

In table 4 are presented the geometrical characteristics of mixer for duty.

\begin{tabular}{|c|c|c|c|}
\hline \multirow{2}{*}{$\begin{array}{c}\text { Current } \\
\text { number }\end{array}$} & \multirow{2}{*}{$\begin{array}{c}\text { The phases } \\
\text { nature }\end{array}$} & $\begin{array}{c}\text { The phases } \\
\text { type }\end{array}$ & $\begin{array}{c}\text { The phases } \\
\text { participation, } \\
\%\end{array}$ \\
\hline \multirow{2}{*}{1} & \multirow{2}{*}{ Liquid } & Water & 75 \\
\cline { 4 - 4 } & & & 50 \\
\hline \multirow{2}{*}{2} & \multirow{2}{*}{ Solid } & $\begin{array}{c}\text { Higher flour } \\
\text { 000 }\end{array}$ & 25 \\
\cline { 4 - 4 } & & & 50 \\
\hline
\end{tabular}

Tab. 1. The type, nature and participation of phases

\begin{tabular}{|c|c|c|c|c|}
\hline \multirow{2}{*}{$\begin{array}{c}\text { Curent } \\
\text { number }\end{array}$} & The property & M.U. & \multicolumn{2}{|c|}{$\begin{array}{c}\text { The phases } \\
\text { type }\end{array}$} \\
\cline { 3 - 5 } & & Wate & $\begin{array}{c}\text { Higher } \\
\text { flour } \\
\text { O00 }\end{array}$ \\
\hline 1 & $\begin{array}{c}\text { The density in } \\
\text { bulk of powder } \\
\text { flour }\end{array}$ & $\mathrm{kg} / \mathrm{m}^{3}$ & - & 1410 \\
\hline 2 & $\begin{array}{c}\text { The density of } \\
\text { water at } \\
\text { operating } \\
\text { temperature }\end{array}$ & $\mathrm{kg} / \mathrm{m}^{3}$ & 998.2 & - \\
\hline 3 & $\begin{array}{c}\text { The temperature } \\
\text { The ash in dry } \\
\text { substance }\end{array}$ & $\%$ & 20 & 20 \\
\hline 5 & The humidity & $\%$ & - & 0.48 \\
\hline 6 & The hardness & $\begin{array}{c}\text { degree.Germa- } \\
\text { ne }\end{array}$ & 14 & - \\
\hline 7 & The fixed residue & $\mathrm{mg} / \mathrm{L}$ & 500 & - \\
\hline
\end{tabular}

Tab. 2 The phases properties

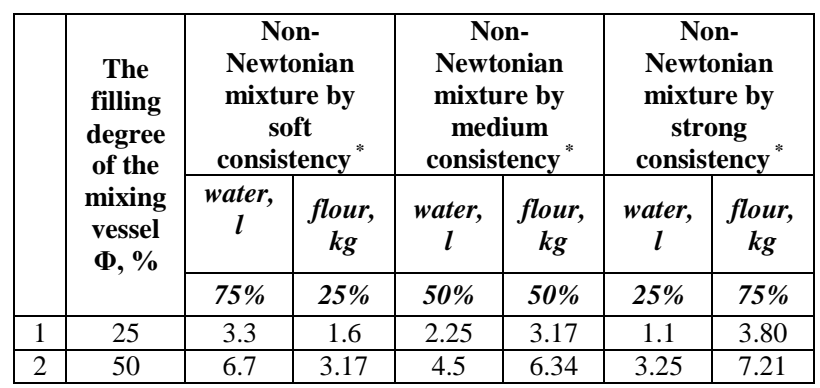

Tab.3. The phases participation depending on the filling degree of the mixing vessel

\begin{tabular}{|c|c|c|c|c|}
\hline \multirow{2}{*}{ C. nu. } & \multirow{2}{*}{ The characteristic } & \multirow{2}{*}{ M. U. } & \multicolumn{2}{|c|}{$\begin{array}{c}\text { The mixing device } \\
\text { type }\end{array}$} \\
\hline & & & & $X$ \\
\hline 1 & $\begin{array}{l}\text { The interior diameter } \\
\text { of the mixing vessel, } \\
\text { D }\end{array}$ & $\mathrm{cm}$ & 28 & 28 \\
\hline 2 & $\begin{array}{l}\text { The diameter of the } \\
\text { circle described by } \\
\text { mixing device, } \mathrm{d}\end{array}$ & $\mathrm{cm}$ & 24 & 24 \\
\hline 3 & $\begin{array}{l}\text { The mixing device } \\
\text { position to bottom of } \\
\text { the vessel, y }\end{array}$ & $\mathrm{cm}$ & 2,8 & 2,8 \\
\hline 4 & $\begin{array}{l}\text { The angle of mixing } \\
\text { devicies axis to the } \\
\text { vessel axis, } \alpha\end{array}$ & degree & 0 & 0 \\
\hline 5 & $\begin{array}{l}\text { The revoluton of } \\
\text { mixing device, } n\end{array}$ & $\mathrm{rot} / \mathrm{min}$ & $\begin{array}{l}150 \\
250 \\
500\end{array}$ & $\begin{array}{l}150 \\
250 \\
500\end{array}$ \\
\hline 6 & $\begin{array}{c}\text { Width of the mixing } \\
\text { device, } \mathrm{B}\end{array}$ & $\mathrm{mm}$ & 5 & 5 \\
\hline 7 & $\begin{array}{c}\text { The number of arms of } \\
\text { mixing device, } \mathrm{N}\end{array}$ & buc & 2 & 4 \\
\hline 8 & $\begin{array}{l}\text { The filling degree of } \\
\text { the vessel, } \Phi\end{array}$ & $\%$ & $\begin{array}{l}25 \\
50\end{array}$ & $\begin{array}{l}25 \\
50\end{array}$ \\
\hline 9 & $\begin{array}{l}\text { The working } \\
\text { temperature, } \mathrm{T}\end{array}$ & ${ }^{\circ} \mathrm{C}$ & $\begin{array}{l}10 \\
20 \\
30\end{array}$ & $\begin{array}{l}10 \\
20 \\
30\end{array}$ \\
\hline 10 & The mixing time, $\mathrm{t}$ & $\mathrm{s}$ & 600 & 600 \\
\hline
\end{tabular}

Tab. 4. Geometrical characteristics of the mixer and working regime

\section{EXPERIMENTAL RESULTS}

For the study of viscosity it was taken in consideration only the maximum torsion moment registered value. Figs. 1 - 3 show the final apparent structural viscosity variations for the three types of nonNewtonian mixtures, for mixing device with 2 arms, to a filling degree of the vessel $\Phi=25 \%$ and mixing time $\mathrm{t}=$ $600 \mathrm{~s}$.

In Figs. 4 - 6 present the final apparent structural viscosity variations for the three types of non-Newtonian mixtures, for mixing device with 2 arms, to a filling degree of the vessel $\Phi=50 \%$ and mixing time $\mathrm{t}=600 \mathrm{~s}$

In Figs. 7 - 9 there are presented the final apparent structural viscosity variations for the three types of nonNewtonian mixtures, for mixing device with 4 arms, to a filling degree of the vessel $\Phi=25 \%$ and mixing time $\mathrm{t}=$ $600 \mathrm{~s}$.

In Figs. 10 - 12 it is shown the final apparent structural viscosity variations for the three types of nonNewtonian mixtures, for mixing device with 4 arms, to a filling degree of the vessel $\Phi=50 \%$ and mixing time $\mathrm{t}=$ $600 \mathrm{~s}$.

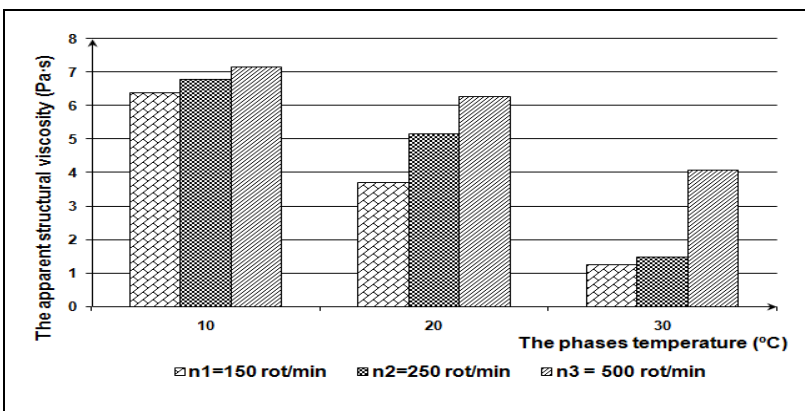

Fig. 1. The variation of the final apparent structural viscosity of the non-Newtonian mixture by soft consistency in function of the phases temperature and mixing devices speed for mixing time $t=600 \mathrm{~s}$ 


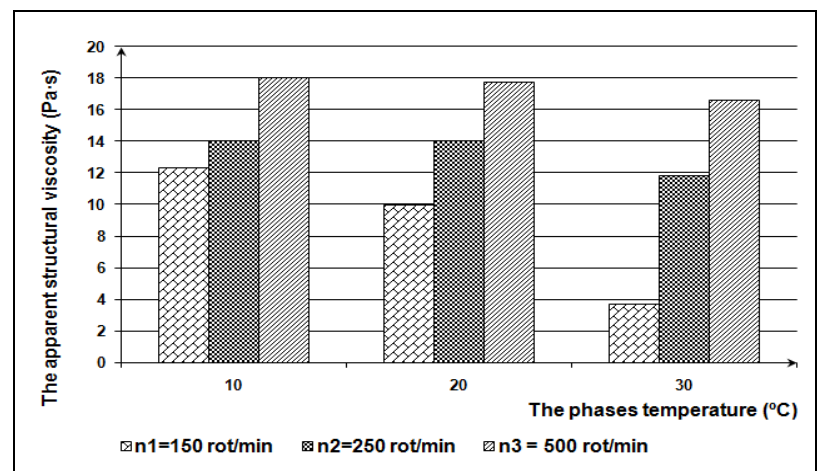

Fig. 2. The variation of the final apparent structural viscosity of the non-Newtonian mixture by medium consistency in function of the phases temperature and mixing devices speed for mixing time $t=600 \mathrm{~s}$

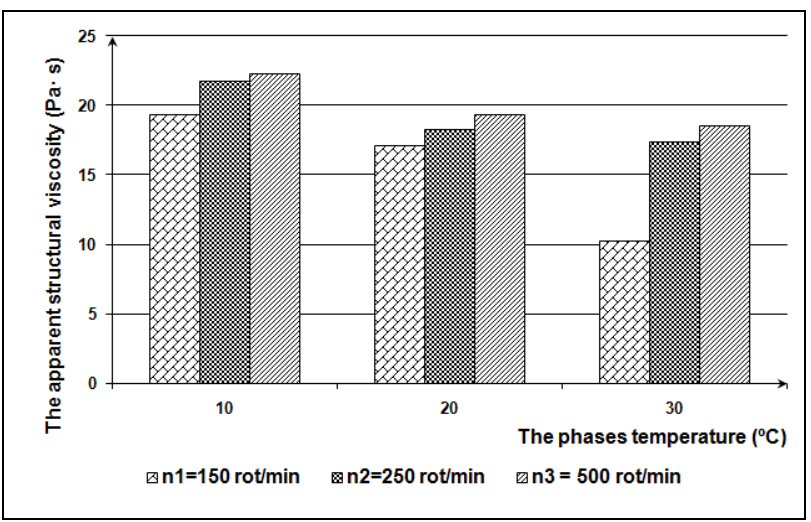

Fig. 3. The variation of the final apparent structural viscosity of the non-Newtonian mixture by strong consistency in function of the phases temperature and mixing devices revolution for mixing time $t=600 \mathrm{~s}$

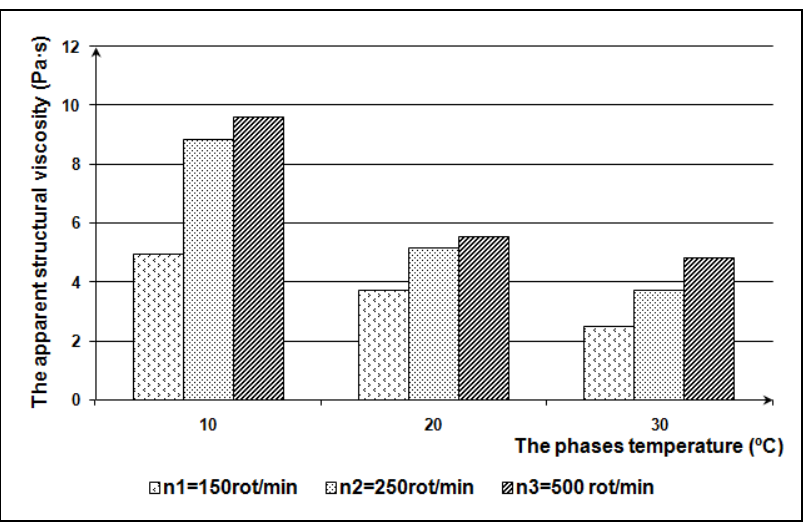

Fig. 4. The variation of the final apparent structural viscosity of the non-Newtonian mixture by soft consistency in function of the phases temperature and mixing devices revolution for mixing time $\mathrm{t}=600 \mathrm{~s}$

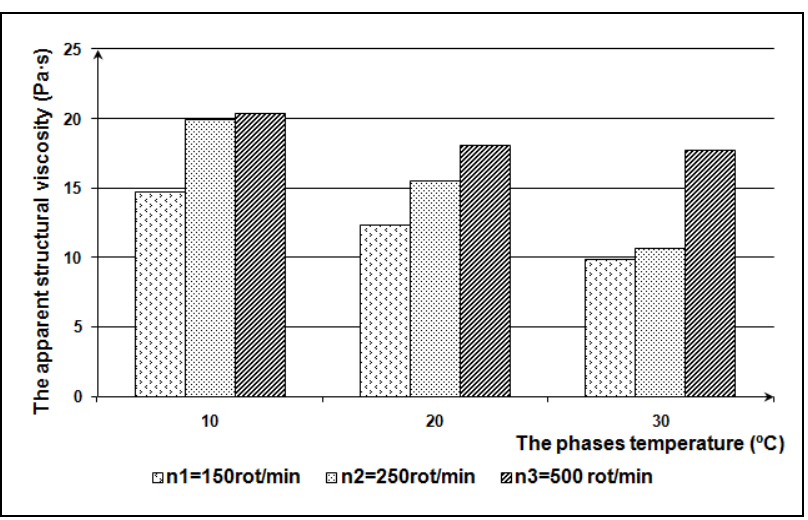

Fig. 5. The variation of the final apparent structural viscosity of the non-Newtonian mixture by medium consistency in function of the phases temperature and mixing devices revolution for mixing time $\mathrm{t}=$ $600 \mathrm{~s}$

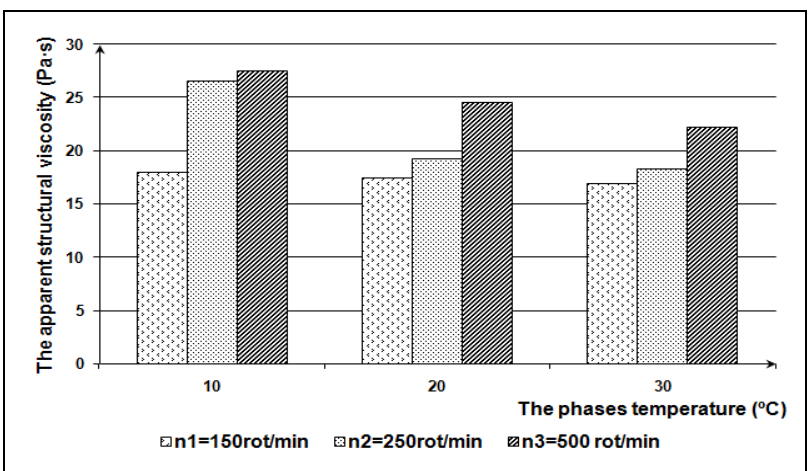

Fig. 6. The variation of the final apparent structural viscosity of the non-Newtonian mixture by strong consistency in function of the phases temperature and mixing devices revolution for mixing time $t=600 \mathrm{~s}$

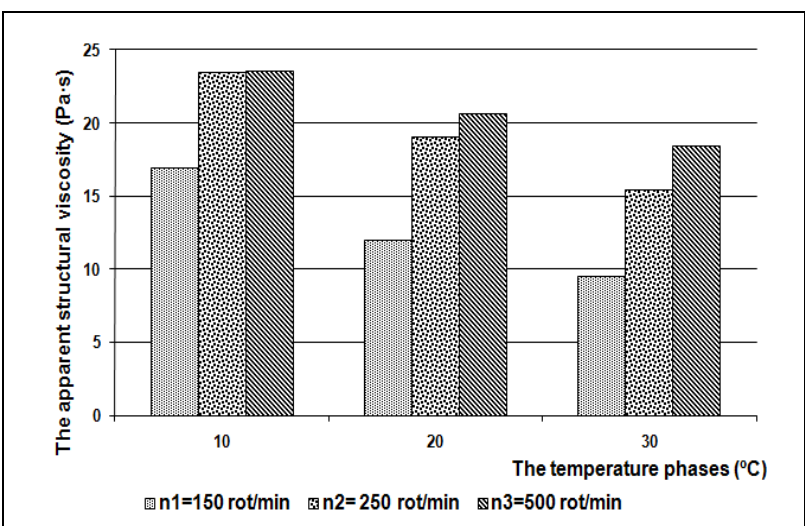

Fig. 7. The variation of the final apparent structural viscosity of the non-Newtonian mixture by soft consistency in function of the phases temperature and mixing devices revolution for mixing time $\mathrm{t}=600 \mathrm{~s}$

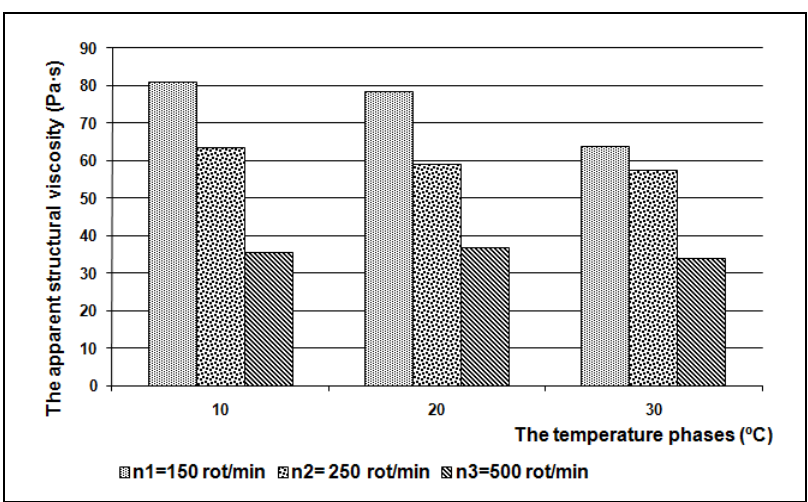

Fig. 8. The variation of the final apparent structural viscosity of the non-Newtonian mixture by medium consistency in function of the phases temperature and mixing devices revolution for mixing time $\mathrm{t}=$ $600 \mathrm{~s}$

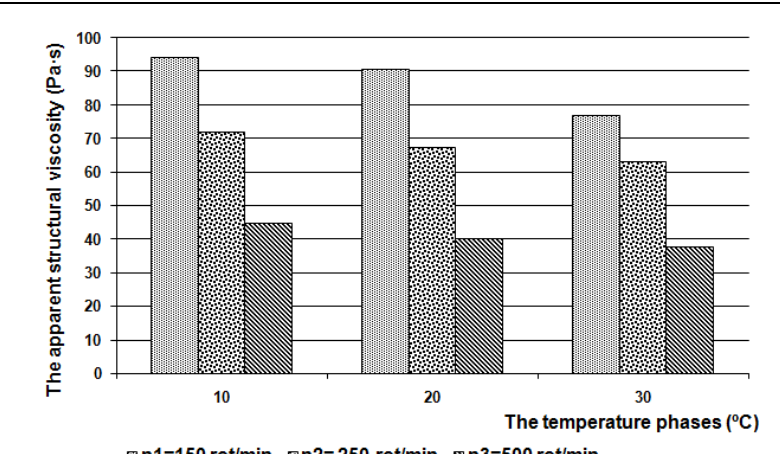

Fig. 9. The variation of the final apparent structural viscosity of the non-Newtonian mixture by strong consistency in function of the phases temperature and mixing devices revolution for mixing time $t=600 \mathrm{~s}$ 


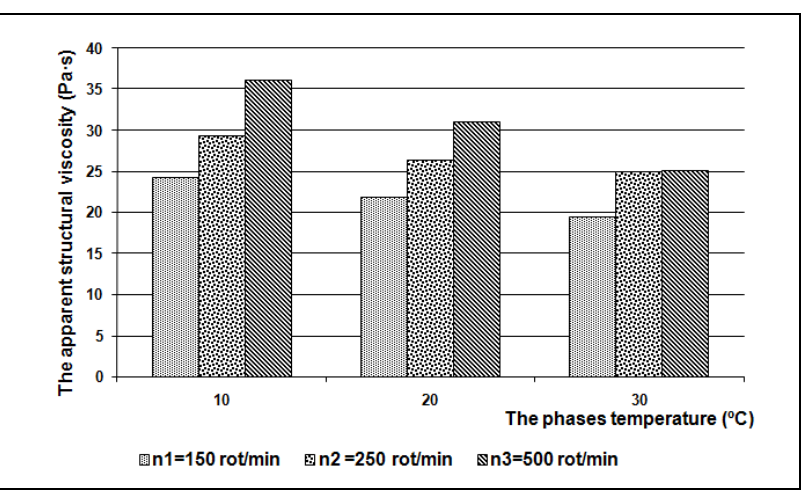

Fig. 10. The variation of the final apparent structural viscosity of the non-Newtonian mixture by soft consistency in function of the phases temperature and mixing devices revolution for mixing time $t=600 \mathrm{~s}$

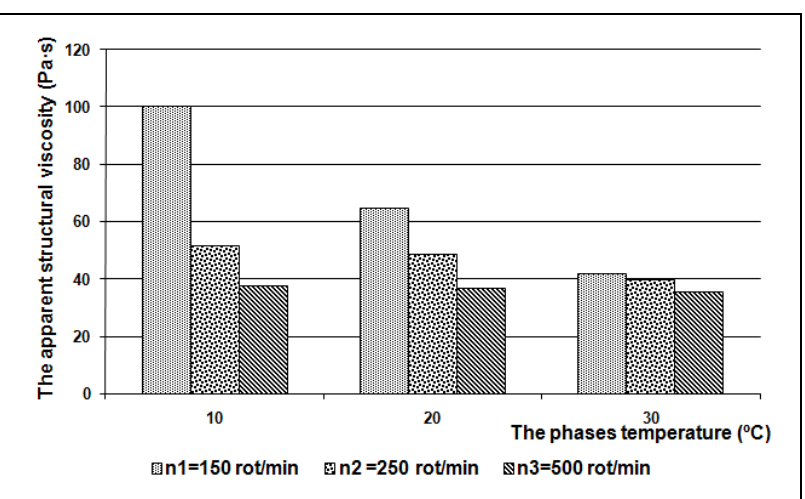

Fig. 11. The variation of the final apparent structural viscosity of the non-Newtonian mixture by medium consistency in function of the phases temperature and mixing devices revolution for mixing time $\mathrm{t}=$ $600 \mathrm{~s}$

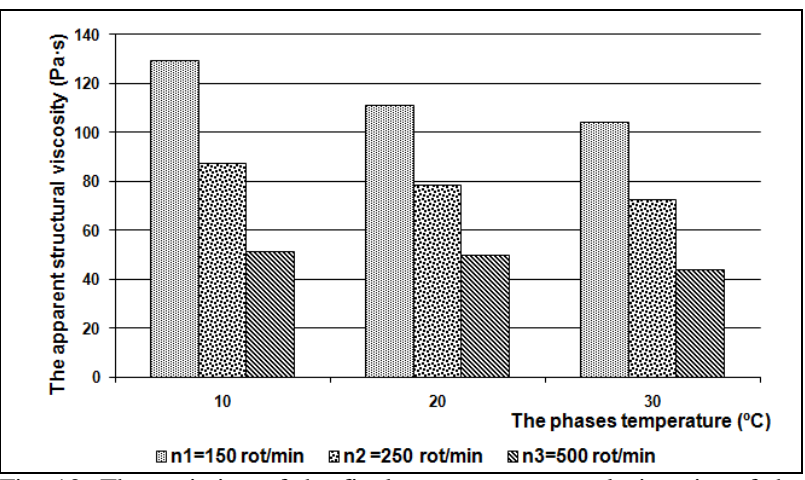

Fig. 12. The variation of the final apparent structural viscosity of the non-Newtonian mixture by strong consistency in function of the phases temperature and mixing devices revolution for mixing time $t=600 \mathrm{~s}$

\section{CONCLUSIONS}

After the experimental determinations in laboratory, concerning the apparent structural viscosity was obtained the following results:

About the three types of non-Newtonian mixtures achieved by mixing device with 2 arms and respectively 4 arms, and the filling degree of the vessel by $25 \%$ and $50 \%$, the mixtures are subjected to simple shear during mixing operation. Application of shear is induced by the rotation of the mixing device driven by an angular velocity $\omega$ and a torque $\mathrm{Mt}$, which depends on the resistance opposed by mixture to flow. In this case, the apparent structural viscosity increases at the beginning of mixing, growth until breaking of the mixture, when the apparent structural viscosity decrease, reaching a constant value towards the end of operation;
During the mixing process, the non-Newtonian mixture is subjected to structural deformation, deformation that increases the internal friction forces, developing heat within the mixture. For the three types of non-Newtonian mixtures, the increase of temperature was negligible $\left(2 \div 3{ }^{\circ} \mathrm{C}\right)$, a minor phenomenon, which led to no changes of non-Newtonian mixture properties;

In case of the three types of mixtures with nonNewtonian blending with 2 arms and filling degree of $25 \%$ and $50 \%$, and the mixture made with soft consistency non-Newtonian device with 4 arms, the structural apparent viscosity decreases with increasing of phases temperature and increases with increasing of mixing devices revolution. In this case, the nonNewtonian mixture presents a dilated behavior;

In case of the non-Newtonian mixture average consistency and strong consistency non-Newtonian mixture blending done with 4 arms and filling degree of the vessel by $25 \%$ and $50 \%$, the apparent structural viscosity decreases with increasing of phases temperature and increase with increasing of mixing device revolution. In this case, mixtures studied present a viscoelastic behavior.

Given the multitude of foods with variable concentrations (dough, pasta, meat, jams, dairy products, etc..) obtained after mixing, it is necessary to study the influence of concentration on the energy mix needed to obtain these products

\section{ACKNOWLEDGEMENTS}

Experimental research is part of the thesis "Research on the optimization of mixing of food products".

\section{REFERENCES}

[1] Moritaka, H. \& Sato E. (2005). "The measurement method of rheology in food", Journal of Japanese Society of Biorheology, Vol. 19, 2005, pp. $116-31$

[2] Nishihara, T., Kaneko, S. \& Watanabe (2005). "Characteristics of fluid dynamic forces acting on a circular cylinder oscillated in the stream wise direction and its wake patterns", Journal of Fluids and Structures, Vol. 20, No. 4, 2005, pp. 505-518

[3] Nedeff, V., Zichil, V., Savin, C., Măcărescu, B., Mosnegutu, E., Panainte M. \& Ambărus, A. (2008). A new method to determinate the viscosity of the non-Newtonian mixtures, Publishing F.M.R., ISSN 1582-2214, 21-26, International Metallurgic

[4] Remmelgas, J., Leal, L.,G., Orr., N.,V. \& Sridhar T.(2006). "Viscous and elastic stress in extensional rheometry", Journal of Non-Newtonian Fluid Mechanics, Vol. 76, No. 1-3, 2006, pp.111113

[5] Savin, C. (2009). Research on optimizing the mixing of food products, Ph.D., The Mechanical Faculty, University "Gheorghe Asachi", Iassi, Romania

[6] Savin, C., Nedeff, V. \& Panainte, M., (2003). Analysis of mixture process for materials with variable viscous. Proceedings of the 14th International DAAAM Symposium Intelligent Manufacturing \& Automation: Focus on Reconstruction and Development, 2003, ISBN 978-3-901509-34-6, Katalinic, B. (Ed.), pp 399-400, Vienna

[7] Savin, C., Zichil, V. \& Judele, A. (2006). The experimental study of structural viscosity which characterized the non-Newtonian food mixtures and process optimatization using finite element method. 17th International Symposium of the Danube-AdriaAssociation-for-Automation-and-Manufacturing, Date: NOV 0811, 2006 Vienna Austria, 17th International DAAAM Symposium, ISBN 978-3-901509-57-5, Katalinic, B. (Ed.) pp. 363-364 Publisher Vienna 